\title{
$\mathrm{Cr}(\mathrm{VI})$-헤테로고리 착물[Cr(VI)-2-methylpyrazine]를 이용한 치환 벤질 알코올류의 산화반응과 메카니즘에 관한 연구
}

\author{
김영식 ${ }^{1}$, 박영조 $^{1^{*}}$ \\ ${ }^{1}$ 강원대학교 화학공학과
}

\section{A Study for Mechanism and Oxidation Reaction of Substituted Benzyl Alcohols using Cr(VI)-Heterocyclic Complex[Cr(VI)-2-methylpyrazine]}

\author{
Young-Sik Kim ${ }^{1}$ and Young-Cho Park $^{1^{*}}$ \\ ${ }^{1}$ Department of Chemical Engineering, Kangwon National University
}

\begin{abstract}
요 약 $\mathrm{Cr}(\mathrm{VI})$-헤테로고리 착물[Cr(VI)-2-methylpyrazine]를 합성하여, 적외선 분광광도법(IR), 유도결합 플라즈마(ICP) 등으로 구조를 확인하였고, 여러 가지 용매 하에서 $\mathrm{Cr}(\mathrm{VI})$-2-methylpyrazine를 이용하여 벤질 알코올의 산화반응을 측 정한 결과, 유전상수 $(\varepsilon)$ 값이 큰 용매 순서인 시클로헥센 < 클로로포름 < 아세톤 < N,N-디메틸포름아미드 용매 하 에서 높은 산화반응성을 보였다. 산 촉매( $\mathrm{HCl})$ 를 이용한 DMF 용매 하에서 $\mathrm{Cr}(\mathrm{VI})-2$-methylpyrazine은 벤질 알코올 $(\mathrm{H})$ 과 그의 유도체들 $\left(\mathrm{p}-\mathrm{CH}_{3}, \mathrm{~m}-\mathrm{Br}, \mathrm{m}-\mathrm{NO}_{2}\right)$ 을 효과적으로 산화시켰다. 전자받개 그룹들은 반응 속도가 감소한 반면에 전 자주개 치환체들은 반응속도를 증가시켰고, Hammett 반응상수 $(\rho)$ 값은 $\mathrm{Cr}(\mathrm{VI})-2-m e t h y l p y r a z i n e=-0.65(308 \mathrm{~K})$ 이였다. 본 실험에서 알코올의 산화반응 과정은 먼저 크로메이트 에스테르 형성과정을 거친 후, 속도결정단계에서 수소화 전 이가 일어나는 메카니즘임을 알 수 있었다.
\end{abstract}

\begin{abstract}
Cr}(\mathrm{VI})$-heterocyclic complex[Cr(VI)-2-methylpyrazine] was synthesized by the reaction between of heterocyclic compound(2-methylpyrazine) and chromium trioxide, and characterized by IR and ICP analysis. The oxidation of benzyl alcohol using $\mathrm{Cr}(\mathrm{VI})$-2-methylpyrazine in various solvents showed that the reactivity increased with the increase of the dielectric $\operatorname{constant}(\varepsilon)$, in the order : cyclohexene $<$ chloroform $<$ acetone $<\mathrm{N}, \mathrm{N}$-dimethylformamide(DMF). In the presence of DMF solvent with acidic catalyst such as hydrochloric $\operatorname{acid}(\mathrm{HCl}$ solution), $\mathrm{Cr}(\mathrm{VI})-2-$ methylpyrazine oxidized benzyl alcohol(H) and its derivatives(p- $\mathrm{CH} 3, \mathrm{~m}-\mathrm{Br}$, $\mathrm{m}-\mathrm{NO} 2$ ). Electron-donating substituents accelerated the reaction, whereas electron acceptor groups retarded the reaction. The Hammett reaction $\operatorname{constant}(\rho)$ was $\mathrm{Cr}(\mathrm{VI})-2$-methylpyrazine $=-0.65(308 \mathrm{~K})$. The observed experimental data have been ratiolized. The hydride ion transfer causes the prior formation of a chromate ester in the rate-determining step.
\end{abstract}

Key Words : Chromate ester, Hydride ion transfer, Hammett reaction constant $(\rho)$, Rate-determining, Step.substituted benzyl alcohol.

1. 서 론

$\mathrm{Cr}(\mathrm{VI})$-유도체들이 유기화합물의 산화제로 널리 이용
되어 왔으나, 이 시약들은 일차 알코올의 산화제로 사용 했을 경우에 생성되는 알데히드가 더욱 산화되어 카르복 시산이 되므로 유기성인 순수 알데히드를 얻기가 힘들다.

${ }^{*}$ Corresponding Author : Young-Cho Park(Kangwon National Univ.)

Tel: +82-10-8799-0255 email: youngjop@hanmail.net 
$\mathrm{Cr}(\mathrm{VI})$-계열의 시약은 보통 수용성이며 유기용매에 불용 성이어서 산화반응을 수용액에서 수행해야 하는 용매의 선택에 제한점이 있고, 알데히드를 얻기에 많은 난점이 있다. 또한 반응이 쉽게 분해되어 정확한 메카니즘은 아 직도 분명치가 않다. 그러므로 유기 용매에 잘 용해되고, 일차 알코올을 알데히드까지만 산화시키는 산화제의 합 성과 그에 따르는 메카니즘 규명이 필요하게 되었다.

다른 한편으로는 한 분자 내에 여러 가지 hydroxy group이 존재할 때, 특정 hydroxy group만을 선택적으로 산화시키는 산화제에 대해서도 연구가 이루어지고 있 다.(quinolinium dichromate, pyrazinium-N-oxide chlorochromate, tripyridin-ium hydrochloride chlorochromate, naphthyridinium dichromate, pyridinium chlorochromate, bipyridinium chlorochromate)[2-7,8,11].

그러므로 유기합성 과정에서 한 분자 내에 여러 가지 hydroxy group(benzylic, allylic, primary, secondary)이 존 재하고 있을 때, 특정 hydroxy group만을 선택적으로 carbonyl compound로 전환시키는 산화제와 그에 따르는 메카니즘 규명이 필요하다.

$\mathrm{Cr}(\mathrm{VI})$-계열의 시약을 이용한 보고된 연구를 보면 Banerji등[1,2]은 pyridinium chlorochromate (Corey's reagent)에 의한 glycollic, lactic 및 a- hydroxybutyric acid 등의 산화에 대한 속도를 연구하였을 뿐만 아니라 과염 소산 존재 하에서 아세트산-물 혼합 용매에서 에틸클로 로카바메이트를 이용하여 벤질 알코올류의 산화에 대한 반응속도론적 연구를 보고하였다. Mahanti등[3-6]은 quinolinium dichromate $(\mathrm{Q})$ 를 이용하여 벤질 알코올류를 산 화 반응시켜 예상되는 두 가지 반응경로의 메카니즘 (Scheme I, Scheme II)을 그림 1에 제시하였다. 보고한 반 응경로의 메카니즘을 고찰해보면, Scheme I 에서는 알코 올과 크롬산이 반응할 때, 속도결정단계에서 양성자 $\left(\mathrm{H}^{+}\right)$ 전이가 직접적으로 일어나므로 활성화 상태에서 알코올 의 a-위치 탄소에 양이온의 생성되는 경로이고, Scheme II 에서는 알코올과 크롬산이 반응할 때 크로메이트 에스 테르(chromate ester)가 먼저 형성된 후 활성화 상태에서 산화제의 $\mathrm{\gamma}$-위치인 $\mathrm{Cr}(\mathrm{VI})$ 에 양이온이 생성된다.

본 실험에서는 유기합성 과정에서 응용범위가 넓고 안 정한 알코올류의 산화제를 개발하기 위하여, $\mathrm{Cr}(\mathrm{VI})$-헤테 로고리 착물 계열인 $\mathrm{Cr}(\mathrm{VI})-2$-methylpyrazine을 합성하여, 적외선분광광도법(IR), 원소분석 등으로 구조를 확인하였 다.

또한 산화반응의 최적 조건을 찾기 위하여 여러 가지 용매 하에서 $\mathrm{Cr}(\mathrm{VI})-2$-methylpyrazine을 이용한 벤질 알코 올의 산화 반응성을 조사하였다. 그리고 $\mathrm{Cr}(\mathrm{VI})-2$-methylpyrazine을 이용하여 벤질 알코올(H)과
그의 유도체들 $\left(\mathrm{p}-\mathrm{CH}_{3}, \mathrm{~m}-\mathrm{Br}, \mathrm{m}-\mathrm{NO}_{2}\right)$ 의 산화반응 속도 실험을 통하여 열역학적 성질 $\left(\Delta \mathrm{H}^{\neq}, \Delta \mathrm{S}^{\neq}, \Delta \mathrm{G}^{7}\right)$ 과 치환 기 효과에 따른 Hammett 반응상수( $\rho$ ) 값 등에서 산화반 응 과정의 메카니즘을 고찰하였다.

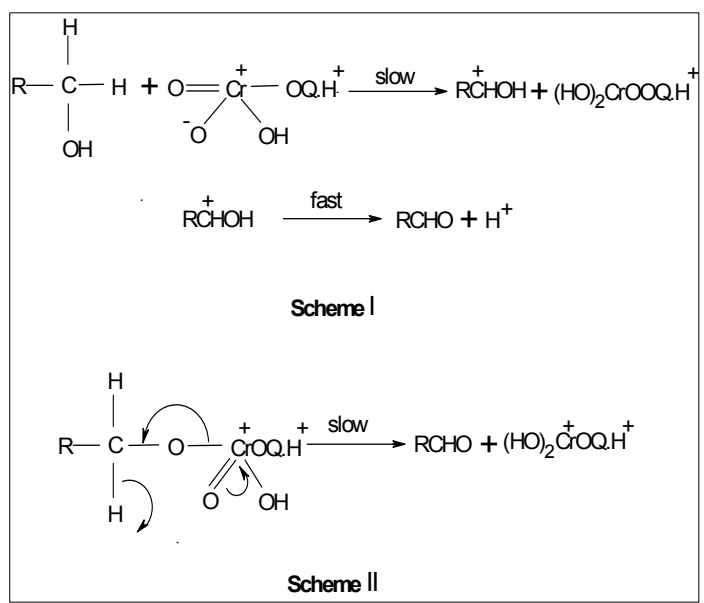

[Fig. 1] Mechanism of the oxidation of substituted benzyl alcohols by quinolinium dichromate

\section{2. 실 험}

\section{1 시약 및 분석기기}

실험에 사용한 2-methylpyrazine 염산 $(\mathrm{HCl})$, chromium(VI)trioxide, 치환 벤질 알코올류 $\left(\mathrm{p}-\mathrm{CH}_{3}, \mathrm{H}\right.$, $\mathrm{m}-\mathrm{Br}, \quad \mathrm{m}-\mathrm{NO}_{2}$ ), 알데히드류, $\mathrm{N}, \mathrm{N}$-디메틸포름아미드 (DMF) 등은 Aldrich 사의 HPLC급 시약을 사용하였다. 녹는점 측정은 Electrothermal 1A 8103 측정기기를 사용 하여 3 회 측정하여 그 평균값을 취하였다. $\mathrm{Cr}$ 정량은 ICP-IRIS(Thermo Jarrell Ash, USA)를 사용하였고, C, H, $\mathrm{N}, \mathrm{O}$ 함량은 elemental anlysis(Vario E L: Germany), FT-IR 측정은 ATI-Mattson 사의 Research series 1 을 사 용하여 측정 하였다. 흡광도 측정은 UV-Visible spectrophotometer(Hewlett Packard UV-8452A)로 absorption $\operatorname{band}\left(\lambda_{\max }\right) \quad 455 \mathrm{~nm}$ 에서 측정하였다. GC-FID(Varian $3400)$ 측정은 capillary column : DB- $5(30 \mathrm{~m} \times 0.253 \mathrm{~mm})$, DB-WAX $(30 \mathrm{~m} \times 0.253 \mathrm{~mm})$, DB- $1(30 \mathrm{~m} \times 0.253 \mathrm{~mm})$, carrier gas로는 $\mathrm{N}_{2}$ 를 사용하여 측정하였다.

\section{2 크롬(VI)-헤테로고리 착물[Cr(VI)-2- methylpyrazine]의 합성}

$6 \mathrm{M}-\mathrm{HCl}$ 용매 하에서 chromium(VI)trioxide, 5.00× $10^{-2}$ mole을 녹인 다음 ice bath에서 $5^{\circ} \mathrm{C}$ 이하로 유지하면 
서 2-methylpyrazine을 $5.00 \times 10^{-2} \mathrm{~mole}$ 을 서서히 가하면서 교반시켜 생성된 결정을 물에서 재결정한 후, 데시케이터 에서 충분히 건조시켜 황색 고체인 $\mathrm{Cr}(\mathrm{VI})-2$-methylpyrazine $\left[\mathrm{C}_{5} \mathrm{H}_{6} \mathrm{~N}_{2} \mathrm{H}-\mathrm{CrO}_{3} \mathrm{Cl}\right]=54 \%$ 를 얻었고, 녹는점은 $148-150^{\circ} \mathrm{C}$ 이였다[7-9]. 그 구조식은 그림 2에 나타내었다. 녹는점 측정은 Electrothermal 1A 8103 측정기기를 사용하여 3회 측정하여 그 평균값을 취하였다. 보고된 문헌[7,8]에서 본 실험과 유사한 $\mathrm{Cr}(\mathrm{VI})$-착물 $\left[\left(\mathrm{C}_{8} \mathrm{H}_{6} \mathrm{~N}_{2} \mathrm{H}\right)_{2} \mathrm{Cr}_{2} \mathrm{O}_{7}\right]$ 인 경우 녹 는점은 $140-142^{\circ} \mathrm{C}$ 을 보였다.

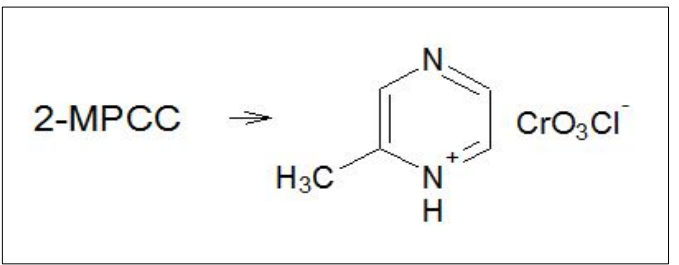

[Fig. 2] $\mathrm{Cr}(\mathrm{VI})$-2-methylpyrazine $\left[\mathrm{C}_{5} \mathrm{H}_{6} \mathrm{~N}_{2} \mathrm{HCrO}_{3} \mathrm{Cl}\right.$ ]

\section{3 여러 가지 용매 하에서 $\mathrm{Cr}(\mathrm{VI})-2-$ methylpyrazine를 이용한 벤질 알코올 의 산화반응성 측정}

$\mathrm{Cr}(\mathrm{VI})$-2-methylpyrazine $2.00 \times 10^{-2}$ mole과 벤질 알코올 $1.00 \times 10^{-2} \mathrm{~mole}$ 을 취하여 실온에서 시클로헥센, 1,4 -디옥 산, 사염화탄소, 클로로포름, 디클로로메탄, 아세톤, DMF 등의 용매 $5 \mathrm{~mL}$ 에 각각 반응시켰다. 최대 수율치가 일정 함을 보일 때까지를 반응종료 시간으로 하여 $\mathrm{GC}$ 로 수율 을 구하였다[4-6,11].

Column: DB-5, DB-WAX, DB-1

Temp: $40^{\circ} \mathrm{C}-80^{\circ} \mathrm{C}, 10^{\circ} \mathrm{C} / \mathrm{min}$ (FID)

Flow rate: $\mathrm{N}_{2}(7 \mathrm{~mL} / \mathrm{min})$

\section{4 산 촉매 존재 하에서 온도변화에 따른 $\mathrm{Cr}(\mathrm{VI})-2-$ methylpyrazine를 이용한 치 환 벤질 알코올류의 산화반응속도 측정}

$\mathrm{Cr}(\mathrm{VI})$-2-methylpyrazine $1.00 \times 10^{-3} \mathrm{~mole}$ 가 함유된 $\operatorname{DMF}(5 \mathrm{~mL})$ 용매 하에서 온도변화 $(303 \mathrm{~K}, 308 \mathrm{~K}, 313 \mathrm{~K})$ 에 따라 치환 벤질 알코올류 $\left(\mathrm{p}-\mathrm{CH}_{3}, \mathrm{H}, \mathrm{m}-\mathrm{Br}, \mathrm{m}-\mathrm{NO}_{2}\right)$ 각각을 $1.00 \times 10^{-1} \mathrm{~mole}$ 첨가한 후, 용액 전체에 산 촉매 $(\mathrm{HCl})$ 농도 가 $5.00 \times 10^{-2}$ mole 되게 신속하게 가한 다음, 시간에 따라 감소하는 흡광도 변화를 측정하였다 $[4-7,10,12,13]$. 흡 광도 값은 최대흡수 파장 $\left(\lambda_{\max }\right) 455 \mathrm{~nm}$ 에서 산화제가 환 원되는 부분을 택하였다. 그리고 속도상수(k) 값은 시간 에 따른 $\log [\mathrm{Cr}(\mathrm{VI})-2$-methylpyrazine] 를 도시하여 구하 였다. 이 속도상수 값으로부터 $\Delta \mathrm{H}^{\neq}, \Delta \mathrm{S}^{\neq}, \Delta \mathrm{G}^{\neq}$와 Hammett 반응상수( $\rho)$ 값을 계산하였다[14-16].

\section{5 활성화 파라미터 계산}

Arrhenius 식[17-21] $\mathrm{k}=\mathrm{A} \cdot \mathrm{e}^{-\frac{\mathrm{E}_{\mathrm{a}}}{\mathrm{RT}}}$ 에 자연대수 를 취하면 다음과 같다.

$$
\ln \mathrm{k}=-\frac{\mathrm{E}_{\mathrm{a}}}{\mathrm{RT}}+\ln \mathrm{A}
$$

식 (1)으로부터 $1 / \mathrm{T}$ 에 대해 $\ln \mathrm{k}$ 를 도시하면 그 기울기 로부터 활성화 에너지 $\mathrm{Ea}$ 를 구할 수 있다. 그리고 활성화 엔탈피와 활성화 엔트로피는 임의의 두 온도 $\mathrm{T}_{\mathrm{i}}$ 와 $\mathrm{T}_{\mathrm{j}}$ 에서 의 Eyring 속도식 (2)와 식 (3)을 아래와 같이 나타낼 수 있다.

$$
\begin{aligned}
& \mathrm{k}_{\mathrm{i}}=\frac{\mathrm{KT}_{\mathrm{i}}}{\mathrm{h}} \mathrm{e}^{\frac{\Delta \mathrm{S}^{*}}{\mathrm{R}}} \cdot \mathrm{e}^{-\frac{\Delta \mathrm{H}^{*}}{\mathrm{RT} \mathrm{T}_{\mathrm{i}}}} \\
& \mathrm{k}_{\mathrm{j}}=\frac{\mathrm{KT} \mathrm{T}_{\mathrm{i}}}{\mathrm{h}} \mathrm{e}^{\frac{\Delta \mathrm{S}^{*}}{\mathrm{R}}} \cdot \mathrm{e}^{-\frac{\Delta \mathrm{H}^{*}}{\mathrm{RT} \mathrm{T}_{\mathrm{j}}}}
\end{aligned}
$$

여기서 $\mathrm{K}$ 는 Boltzmann 상수이고, $\mathrm{h}$ 는 Plank 상수이다. 식 (2)와 식 (3)을 연립으로 풀면,

$$
\begin{aligned}
& \Delta \mathrm{H}^{\neq}=\frac{\mathrm{RT}_{\mathrm{i}} \mathrm{T}_{\mathrm{j}}}{\mathrm{T}_{\mathrm{j}}-\mathrm{T}_{\mathrm{i}}} \ln \frac{\mathrm{k}_{\mathrm{i}} \mathrm{T}_{\mathrm{i}}}{\mathrm{k}_{\mathrm{i}} \mathrm{T}_{\mathrm{j}}} \\
& \Delta \mathrm{S}^{*}=\frac{\mathrm{R}}{\mathrm{T}_{\mathrm{i}}-\mathrm{T}_{\mathrm{j}}} \ln \frac{\left(\frac{\mathrm{k}_{\mathrm{i}}}{\mathrm{T}_{\mathrm{i}}}\right)^{\mathrm{T}_{\mathrm{i}}}}{\left(\frac{\mathrm{k}_{\mathrm{i}}}{\mathrm{T}_{\mathrm{j}}}\right)^{\mathrm{T}_{\mathrm{j}}}}-\mathrm{R} \ln \left(\frac{\mathrm{K}}{\mathrm{h}}\right)
\end{aligned}
$$

식 (4)와 식 (5)에서 $\Delta \mathrm{H}^{\neq}$와 $\Delta \mathrm{S}^{\neq}$를 구하였으며, 활 성화 자유에너지 $\left(\Delta \mathrm{G}^{\neq}\right)$는 식 (6)으로부터 구할 수 있다.

$$
\Delta \mathrm{G}^{*}=\Delta \mathrm{H}^{*}-\mathrm{T} \Delta \mathrm{S}^{\neq}
$$

이 때 $\mathrm{T}$ 는 $\mathrm{T}_{\mathrm{i}}$ 와 $\mathrm{T}_{\mathrm{j}}$ 의 평균값이다.

\subsection{Hammett 반응상수 계산}

많은 $\mathrm{m}$-및 $\mathrm{p}$-치환 벤젠 유도체들의 다양한 반응에 직선관계가 정립되어 있다 하더라도 새로운 반응, 새로운 경우를 대할 때에도 실제로 응용할 수 있는 간단한 정량 적인 관계식이 필요하다. 이에 대한 해결책이 Hammett[17-21]에 의하여 제시 되었다. 제시된 Hammett 방정식을 적용하여 볼 때, 어떠한 치환기에 대해서나 $\log$ $\mathrm{k}_{\mathrm{X}} / \mathrm{k}_{\mathrm{H}}$ 값이 치환기 상수 $\left(\sigma_{\mathrm{X}}\right)$ 로 정의되며, 여기서 $\mathrm{k}_{\mathrm{X}}$ 는 벤 질알코올의 치환체에 대한 속도상수이며, $\mathrm{k}_{\mathrm{H}}$ 는 벤질알코 올에 대한 속도상수이다. 따라서 Hammett 반응상수 $(\rho)$ 를 
식 (7)과 식 (8)같이 정의할 수 있다.

$\log \mathrm{k}_{\mathrm{X}} / \mathrm{k}_{\mathrm{H}}=\rho \cdot \sigma_{\mathrm{X}}$

$$
\rho=\frac{\log \mathrm{k}_{\mathrm{X}} / \mathrm{k}_{\mathrm{H}}}{\sigma_{\mathrm{X}}}
$$

\section{3. 결과 및 고찰}

\section{1 크롬(VI)-헤테로고리 착물 $[\mathrm{Cr}(\mathrm{VI})-2-$ methylpyrazine] 합성에 대한 고찰}

$\mathrm{Cr}$ (VI)-2-methylpyrazine의 적외선 스펙트럼은 그림 3 에 나타내었다.

$\mathrm{Cr}(\mathrm{VI})$-2-methylpyrazine $\left[\mathrm{C}_{5} \mathrm{H}_{6} \mathrm{~N}_{2} \mathrm{HCrO}_{3} \mathrm{Cl}\right]$ 의 적외선 스 펙트럼을 고찰해보면, $V_{\text {asym. }}(\mathrm{Cr}-\mathrm{O}): \quad 950,930 \mathrm{~cm}^{-1}, \mathrm{~V}$ sym.(Cr-O): $900 \mathrm{~cm}^{-1}, \mathrm{v}(\mathrm{Cr}-\mathrm{Cl}): 430 \mathrm{~cm}^{-1}, \mathrm{v}(\mathrm{N}-\mathrm{H}): 3450 \mathrm{~cm}^{-1}, \mathrm{v}$ $(\mathrm{C}-\mathrm{H}): 3050 \mathrm{~cm}^{-1}, \mathrm{v}(\mathrm{C}=\mathrm{C}): 1600 \mathrm{~cm}^{-1}, \mathrm{v}(\mathrm{N}-\mathrm{H}): 1540 \mathrm{~cm}^{-1}, \mathrm{v}$ (C-H): $1400 \mathrm{~cm}^{-1}, \mathrm{v}(\mathrm{C}-\mathrm{N}): 1200 \mathrm{~cm}^{-1}$ 흡수 peak가 나타났다 $[7,8]$.

원소분석 결과는 표 1 에 나타내었다. 원소분석에서 이 론값과 측정값이 잘 일치함을 보였다.

결과적으로 본 실험과 유사한 $\mathrm{Cr}(\mathrm{VI})$-착물[7,8]의 적외 선 스펙트럼(IR)과 원소분석을 비교해본 결과 잘 일치하 였고, 참고문헌[7-8] 값 등으로부터 고찰해본 결과 착물 이 합성됨을 확인하였다.

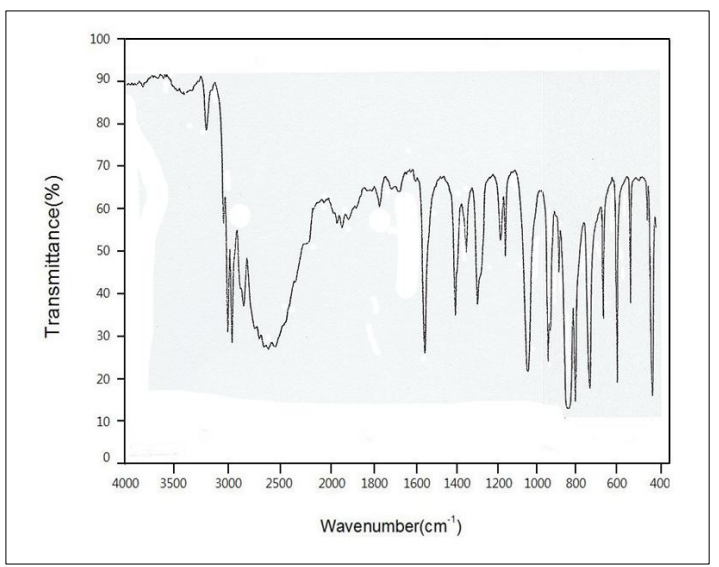

[Fig. 3] IR spectrum of $\mathrm{Cr}(\mathrm{VI})-2$-methylpyrazine $\left.\left[\mathrm{C}_{5} \mathrm{H}_{6} \mathrm{~N}_{2} \mathrm{HCrO}_{3} \mathrm{Cl}\right]\right]$
[Table 1] Elemental analysis of $\mathrm{Cr}(\mathrm{VI})$-2-methyl-pyrazine

\begin{tabular}{|c|c|c|c|c|c|}
\hline Complex & \multicolumn{5}{|c|}{ Elemental } \\
\hline $\begin{array}{c}\text { Calculated } \\
\mathrm{C}_{5} \mathrm{H}_{6} \mathrm{~N}_{2} \mathrm{H}- \\
\mathrm{CrO}_{3} \mathrm{Cl}\end{array}$ & $\mathrm{C}$ & $\mathrm{H}$ & $\mathrm{N}$ & $\mathrm{O}$ & $\mathrm{Cr}$ \\
\hline Found & $26.05 \%$ & $3.06 \%$ & $12.15 \%$ & $36,24 \%$ & $22.50 \%$ \\
\hline
\end{tabular}

\section{2 여러 가지 용매 하에서 $\mathrm{Cr}(\mathrm{VI})-2-$ methylpyrazine를 이용한 벤질 알코올 의 산화반응성 고찰}

시클로헥센, 1,4-디옥산, 사염화탄소, 클로로포름, 디클 로로메탄, 아세톤, $\mathrm{DMF}$ 등의 용매 하에서, $\mathrm{Cr}(\mathrm{VI})$-2-methylpyrazine를 이용하여 벤질 알코올을 각각 산화반응 시켰다. 생성된, 알데히드의 수율을 $\mathrm{GC}$ 로 분석 하여, 최대 수율치가 일정함을 보일 때까지를 반응종료 시간으로 하여 $\mathrm{GC}$ 로 수율을 구하였고 표 2에 나타내었 다. 그리고 $\mathrm{GC}$ 크로마토그램에서 벤즈알데히드 표준물 질과 벤질 알코올의 산화반응시 생성되는 벤즈알데히드 을 비교하였다. $\mathrm{Cr}(\mathrm{VI})-2$-methylpyrazine은 1,4-디옥산, 시 클로헥센 등에는 용해되지 않았고, 클로로포름, 아세톤, 디클로로메탄 등에는 일부가 용해되었고, N,N'-디메틸포 름아미드 등에는 모두 용해되었다. 시클로헥센<클로로포 름<아세톤<DMF 용매 순으로 높은 산화반응성을 보였 다.

최대 수율치가 일정함을 보일 때까지를 반응종료 시간 으로 하여 $\mathrm{GC}$ 로 수율을 구하였다

[Table 2] Summarized results of oxidation of benzyl alcohol using $\mathrm{Cr}(\mathrm{VI})$-2-methylpyrazine in various solvents ${ }^{\text {a) }}$

\begin{tabular}{|c|c|c|c|}
\hline Solvents & $\begin{array}{c}\varepsilon^{\mathrm{b})} \text { at } \\
25^{\circ} \mathrm{C}\end{array}$ & $\begin{array}{c}\text { Yield of } \\
\text { benza- } \\
\text { 1dehyde } \\
(\%)^{\mathrm{c})}\end{array}$ & Time(h) \\
\hline cyclohexene & 2.22 & 32 & 1.6 \\
1,4-dioxane & 2.21 & 36 & 2.0 \\
carbontetrachloride & 2.24 & 57 & 1.7 \\
chloroform & 4.81 & 85 & 2.2 \\
dichloromethane & 8.93 & 87 & 2.1 \\
acetone & 20.70 & 91 & 1.7 \\
N,N'-dimethylform- & 37.00 & 94 & 2.2 \\
amide & & & \\
\hline
\end{tabular}

a) Benzyl alcohol $\left(1.00 \times 10^{-2}\right.$ mole $)$ and $\mathrm{Cr}(\mathrm{VI})-2$-methylpyrazine $\left(2.00 \times 10^{-2}\right.$ mole $)$ were combined in various solvents and then the mixtures were stirred at room temperature.

b) Dielectric constant.

c) Yields were calculated on the basis of GC data. 


\section{3 산 촉매 존재하에서 온도변화에 따른 $\mathrm{Cr}(\mathrm{VI})-2-$ methylpyrazine를 이용한치환 벤질 알코올류의 산화반응속도 측정 고찰}

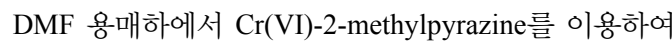
치환된 벤질 알코올류 $\left(\mathrm{p}-\mathrm{CH}_{3}, \mathrm{H}, \mathrm{m}-\mathrm{Br}, \mathrm{m}-\mathrm{NO}_{2}\right)$ 를, 산 $(\mathrm{HCl})$ 촉매를 첨가하여 온도변화 $(303 \mathrm{~K}, 308 \mathrm{~K}, 313 \mathrm{~K})$ 에 따라 각각 반응시켜 속도상수를 구하였고, 치환 벤질 알 코올류의 농도를 산화제의 농도에 비하여 과량으로 취하 여 유사일차 반응으로 진행시켰다. 이 속도상수 $(\mathrm{k})$ 값으 로부터 열역학적 활성화 파라미터 $\left(\Delta \mathrm{H}^{\neq}, \Delta \mathrm{S}^{\neq}, \Delta \mathrm{G}^{\neq}\right)$값과 치환기 효과에 따른 Hammett 반응상수( $\rho)$ 값을 계산하였 다.

표 3와 표 4에서 나타낸 바와 같이 산 촉매를 첨가한 경우, $\mathrm{k}$ 값은 온도가 증가함에 따라 증가하였고, 치환기 효과는 전자를 주는 치환기 $\mathrm{p}-\mathrm{CH}_{3}$ 에서 $\mathrm{k}$ 값이 증가하였 다. 또한 $\Delta \mathrm{H}^{\neq}$가 양의 값을, $\Delta \mathrm{S}^{\neq}$가 음의 값을 나타낸 것 으로 보아, 산화반응 과정에서 전자를 주는 치환기가 있 을 경우, 반응물보다 전이상태인 활성화 착물에서 더 안 정화됨을 알 수 있었다. 그리고 $\Delta \mathrm{G}^{\neq}$가 일정한 양의 값을 보였다.

[Table 3] Rate constants for the oxidation of substituted benzyl alcohols ${ }^{\text {a) }}$ using $\mathrm{Cr}(\mathrm{VI})-2$-methylpyrazine ${ }^{\text {b) }}$ in thepresence ofacid $[\mathrm{HCl}]^{\mathrm{c}}$

\begin{tabular}{|c||ccc|}
\hline \multirow{2}{*}{ Substituents } & \multicolumn{3}{c|}{ Rate constant $10^{5} \mathrm{k}\left(\mathrm{s}^{-1}\right)$} \\
& $303 \mathrm{~K}$ & $308 \mathrm{~K}$ & $313 \mathrm{~K}$ \\
\hline \hline $\mathrm{p}-\mathrm{CH}_{3}$ & 6.01 & 7.82 & 8.19 \\
$\mathrm{H}$ & 5.05 & 4.65 & 6.22 \\
$\mathrm{~m}-\mathrm{Br}$ & 2.99 & 2.96 & 3.85 \\
$\mathrm{~m}-\mathrm{NO}_{2}$ & 2.08 & 2.33 & 3.04 \\
\hline
\end{tabular}

a) $1.00 \times 10^{-1}$ mole. b) $1.00 \times 10^{-3}$ mole. c) $5.00 \times 10^{-2}$ mole.

[Table 4] Activation parameters for the oxidation of substituted benzyl alcohols in Table 3

\begin{tabular}{|c||ccc|}
\hline Substituents & $\begin{array}{c}\Delta \mathrm{H}^{\neq} \\
\left(\mathrm{KJmol}^{-1}\right)\end{array}$ & $\begin{array}{c}\Delta \mathrm{S}^{\neq} \\
\left(\mathrm{Jmol}^{-1} \mathrm{~K}^{-1}\right)\end{array}$ & $\begin{array}{c}\Delta \mathrm{G}^{\neq} \\
\left(\mathrm{KJmol}^{-1}\right)\end{array}$ \\
\hline \hline $\mathrm{p}-\mathrm{CH}_{3}$ & 26.89 & -236 & 101.634 \\
$\mathrm{H}$ & 31.24 & -227 & 101.257 \\
$\mathrm{~m}-\mathrm{Br}$ & 36.79 & -234 & 101.154 \\
$\mathrm{~m}-\mathrm{NO}_{2}$ & 39.97 & -222 & 102.937 \\
\hline
\end{tabular}

또한 표 5와 표 6에서 산 촉매를 첨가하지 않은 경우, 산 촉매를 첨가했을 때와 비교해보면, $\mathrm{p}-\mathrm{CH}_{3}$ 에서 $\mathrm{k}$ 값이 감소하였고, 전자를 받는 치환기 $\mathrm{m}-\mathrm{Br}, \mathrm{m}-\mathrm{NO}_{2}$ 에서 $\mathrm{k}$ 값 이 조금 증가한 것으로 보아, 속도결정단계에서 산 촉매
의 존재가 촉매 작용으로 산화반응 속도를 촉진시키는 역할을 한 것으로 생각된다.

[Table 5] Rate constants for the oxidation of substituted benzyl alcohols ${ }^{\text {a) }}$ using $\mathrm{Cr}(\mathrm{VI})-2$ - methylpyrazine ${ }^{\text {b) }}$

\begin{tabular}{|c||ccc|}
\hline \multirow{2}{*}{ Substituents } & \multicolumn{3}{|c|}{ Rate constant $\left.10^{5} \mathrm{k}^{-1}\right)$} \\
& $303 \mathrm{~K}$ & $308 \mathrm{~K}$ & $313 \mathrm{~K}$ \\
\hline \hline $\mathrm{p}-\mathrm{CH}_{3}$ & 4.08 & 4.93 & 5.57 \\
$\mathrm{H}$ & 3.76 & 4.39 & 4.34 \\
$\mathrm{~m}-\mathrm{Br}$ & 3.01 & 3.12 & 3.95 \\
$\mathrm{~m}-\mathrm{NO}_{2}$ & 2.58 & 2.79 & 3.24 \\
\hline
\end{tabular}

a) $1.00 \times 10^{-1}$ mole. b) $1.00 \times 10^{-3}$ mole.

[Table 6] Activation parameters for the oxidation of substituted benzyl alcohols in Table 5

\begin{tabular}{|c||ccc|}
\hline Substituents & $\begin{array}{c}\Delta \mathrm{H}^{\mp} \\
\left(\mathrm{KJmol}^{-1}\right)\end{array}$ & $\begin{array}{c}\Delta \mathrm{S}^{\mp} \\
\left(\mathrm{Jmol}^{-1} \mathrm{~K}^{-1}\right)\end{array}$ & $\begin{array}{c}\Delta \mathrm{G}^{\neq} \\
\left(\mathrm{KJmol}^{-1}\right)\end{array}$ \\
\hline \hline $\mathrm{p}-\mathrm{CH}_{3}$ & 18.12 & -259 & 101.954 \\
$\mathrm{H}$ & 17.97 & -251 & 102.890 \\
$\mathrm{~m}-\mathrm{Br}$ & 19.98 & -247 & 103.120 \\
$\mathrm{~m}-\mathrm{NO}_{2}$ & 21.93 & -220 & 104.374 \\
\hline
\end{tabular}

그러나 표 7와 표 8에서 산 촉매를 첨가하지 않고 산 화제의 농도를 높인 경우, $\mathrm{p}-\mathrm{CH}_{3}$ 와 $\mathrm{m}-\mathrm{Br}, \mathrm{m}-\mathrm{NO}_{2}$ 에서 $\mathrm{k}$ 값이 산화제의 농도가 낮을 때와 크게 차이가 없는 것으 로 보아 산화제의 농도가 산화반응 속도에 거의 영향을 미치지 않은 것으로 생각된다.

[Table 7] Rate constants for the oxidation of substituted benzyl alcohols ${ }^{\text {a) }}$ using $\mathrm{Cr}(\mathrm{VI})-2$-methylpyrazine ${ }^{\text {b) }}$

\begin{tabular}{|c||ccc|}
\hline \multirow{2}{*}{ Substituents } & \multicolumn{3}{|c|}{ Rate constant $\left.10^{5} \mathrm{k}^{-1} \mathrm{~s}^{-1}\right)$} \\
& $303 \mathrm{~K}$ & $308 \mathrm{~K}$ & $313 \mathrm{~K}$ \\
\hline \hline $\mathrm{p}-\mathrm{CH}_{3}$ & 4.89 & 4.79 & 5.39 \\
$\mathrm{H}$ & 3.25 & 3.98 & 5.06 \\
$\mathrm{~m}-\mathrm{Br}$ & 3.02 & 3.07 & 4.69 \\
$\mathrm{~m}-\mathrm{NO}_{2}$ & 2.55 & 2.62 & 3.56 \\
\hline
\end{tabular}

a) $1.00 \times 10^{-1}$ mole. b) $3.00 \times 10^{-3}$ mole.

[Table 8] Activation parameters for the oxidation of substituted benzyl alcohols in Table 7

\begin{tabular}{|c||ccc|}
\hline Substituents & $\begin{array}{c}\Delta \mathrm{H}^{\neq} \\
\left(\mathrm{KJmol}^{-1}\right)\end{array}$ & $\begin{array}{c}\Delta \mathrm{S}^{\neq} \\
\left(\mathrm{Jmol}^{-1} \mathrm{~K}^{-1}\right)\end{array}$ & $\begin{array}{c}\Delta \mathrm{G}^{\neq} \\
\left(\mathrm{KJmol}^{-1}\right)\end{array}$ \\
\hline \hline $\mathrm{p}-\mathrm{CH}_{3}$ & 20.13 & -240 & 102.468 \\
$\mathrm{H}$ & 23.07 & -251 & 103.273 \\
$\mathrm{~m}-\mathrm{Br}$ & 23.91 & -217 & 103.824 \\
$\mathrm{~m}-\mathrm{NO}_{2}$ & 25.28 & -227 & 104.572 \\
\hline
\end{tabular}


속도 자료를 이용한 Hammett 도시로부터 구한 반응상 수 값을 고찰해 보면, 그림 4에서 나타낸 바와 같이 산 촉 매를 첨가한 경우 $\rho$ 값은 -0.65 로 나타났다. 그러나 산 촉 매를 첨가하지 않은 경우 표 5에서 구하면 $\rho$ 값은 -0.28 로 감소하였다. 산 촉매를 첨가했을 경우 음의 $\rho$ 값이 증가한 원인은 알코올과 크롬산이 산화반응 과정에서 크로메이 트 에스테르 형성이 일어날 때, 산 촉매 존재에서 양성자 가 첨가로 인해, $\mathrm{Cr}(\mathrm{VI})$ 에 양이온을 안정화시켜 주는 역 할을 하였기 때문이다. 이러한 결과로 치환된 벤질 알코 올류에 따라 $\mathrm{k}$ 값의 차이가 커짐으로 인하여 $-\mathrm{\rho}$ 값이 증가 하였다. 그러나 산 촉매를 첨가하지 않고 산화제의 농도 를 높인 경우 표 7 에서 구하면 $\mathrm{\rho}$ 값은 -0.28 로 나타났다. 산 촉매를 첨가하지 않고 산화제 농도가 낮은 경우와 차 이가 없는 것으로 보아, $\mathrm{k}$ 는 산화제의 농도에 의존하지 않음을 알 수 있었다.

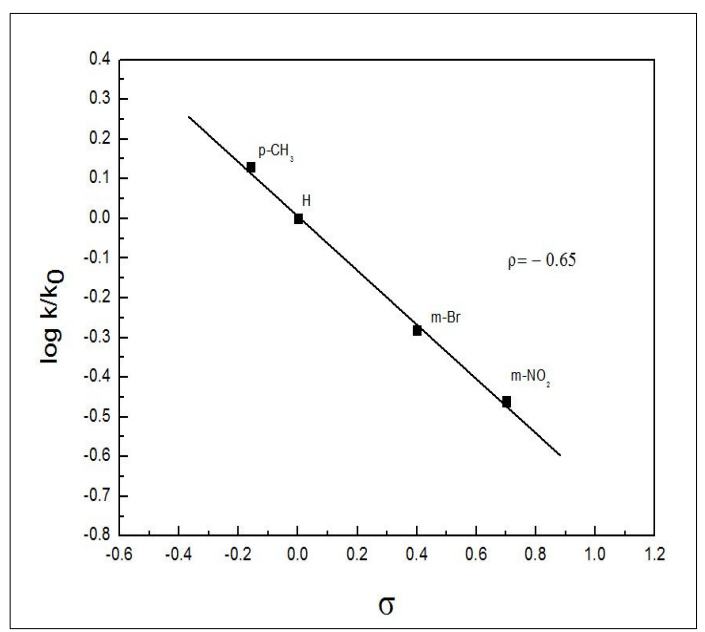

[Fig. 4] The Hammett polt for the oxidation of substituted benzyl alcohols ${ }^{\text {a) }}$ by $\mathrm{Cr}(\mathrm{VI})-2$ methylpyrazine ${ }^{\text {b) }}$ in the presence of acid $[\mathrm{HCl}]^{\mathrm{c})}$ at $308 \mathrm{~K}$. a) $1.00 \times 10^{-1}$ mole. b) $1.00 \times 10^{-3}$ mole. c) $5.00 \times 10^{-2}$ mole.

그러므로 본 실험결과를 통하여 Mahanti등[4-7]이 보 고한 그림 1에서 메카니즘을 고찰해보면, Scheme I 에서 는 알코올과 크롬산이 반응할 때, 속도결정단계에서 수소 화전이가 직접적으로 일어나므로 활성화 상태에서 알코 올의 a-위치 탄소에 양이온의 생성되는 경로로 높은 -p 값이 예상된다. 그러나 Scheme II에서는 알코올과 크롬 산이 반응할 때 크로메이트 에스테르가 먼저 형성된 후 활성화 상태에서 산화제의 $\mathrm{\gamma}$-위치인 $\mathrm{Cr}(\mathrm{VI})$ 에 양이온이 생성되므로 치환기 효과가 적어 낮은 - $\mathrm{p}$ 값이 예상된다. 그러므로 보고된 문헌의 $\rho=-1.71$ 값에 비해, 본 실험에서
얻은 $\rho=-0.65$ 값이 더 낮은 음에 값이 나타났고, 산 촉매 를 첨가시키지 않은 경우 더욱 낮은 $\rho=-0.28$ 값이 나타났 다. 이러한 결과들을 볼 때, 그림 5 에서와 같이 $\mathrm{Cr}(\mathrm{VI})$-2-methylpyrazine와 알코올의 산화반응 과정에서 먼저 크로메이트 에스테르 형성과정을 거친 후, 속도결정 단계에서 수소화 전이가 일어나는 메카니즘으로 예상 된 다.

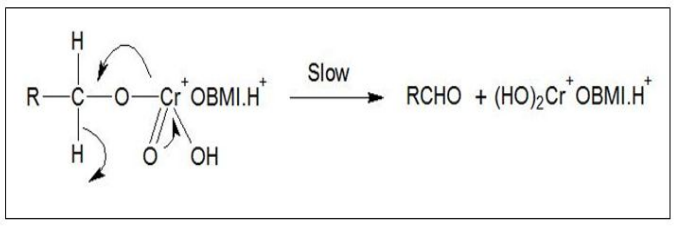

[Fig. 5] Mechanism of the oxidation of substituted benzyl alcohols by BMI[Cr(VI)-2-methylpyrazine]

\section{4. 결 론}

유기합성 과정에서 응용범위가 넓고 안정한 알코올류 의 산화제를 개발하기 위하여, $\mathrm{Cr}(\mathrm{VI})$-헤테로고리 착물인 $\mathrm{Cr}(\mathrm{VI})-2$-methylpyrazine를 합성하여 구조를 확인하였다.

또한 여러 가지 용매 하에서 $\mathrm{Cr}(\mathrm{VI})-2$-methy- lpyrazine 과 벤질 알코올의 산화반응성을 조사하였다.

그리고 산 촉매 존재 하에서 온도변화에 따른 $\mathrm{Cr}(\mathrm{VI})-2$-methylpyrazine을 이용한 치환 벤질 알코올류의 산화반응속도 측정 실험을 하였다.

이상과 같은 실험에서 다음과 같은 결론을 얻었다.

1. 여러 가지 용매 하에서 $\mathrm{Cr}(\mathrm{VI})-2$-methylpyr azine과 벤질 알코올의 산화반응을 측정한 결과 시클로헥 센<클로로포름<아세톤<DMF 용매 하에서 높은 산 화반응성을 보였다.

2. 산 촉매 $(\mathrm{HCl})$ 존재 하에서 온도변화에 따른 $\mathrm{Cr}(\mathrm{VI})$-2-methylpyrazine과 치환 벤질 알코 올류 $\left(\mathrm{p}-\mathrm{CH}_{3}, \mathrm{H}, \mathrm{m}-\mathrm{Br}, \mathrm{m}-\mathrm{NO}_{2}\right)$ 와의 산화반응 속도를 측 정한 결과 $\Delta \mathrm{H}^{\neq}$가 양의 값을, $\Delta \mathrm{S}^{\neq}$가 음의 값을 보 였다.

3. Hammett 반응상수 $(\rho)$ 값은 $\mathrm{Cr}(\mathrm{VI})-2$-methyl-pyrazine= $-0.65(308 \mathrm{~K})$ 를 나타났다.

4. $\mathrm{Cr}(\mathrm{VI})-2-\mathrm{methylpyrazine}$ 과 알코올의 산화반 응 과 정에서 먼저 크로메이트 에스테르 형성과정을 거친 후, 속도결정단계에서 수소화 전이가 일어나는 반 응경로가 예상 된다. 


\section{References}

[1] K. K. Banerji, "Kinetic Study of the Oxidation of Substituted Benzyl Alcohols by Ethyl Chlorochromate", Bull. Chem. Soc. Japan, 61, 5, pp. 1767-1771, 1988. DOI: http://dx.doi.org/10.1246/bcsj.61.1767

[2] J. F. Kuo, "Chromium(VI) Complexation with Triisooctylamine in Organic Solvents", Bull. Chem. Soc. Japan, 64, 10, pp. 3059-3062, 1991.

DOI: http://dx.doi.org/10.1246/bcsj.61.1767

[3] M. K. Mahanti, D. Dey, "Kinetics of Oxidation of Substituted Benzyl Alcohols by Quinolinium Dichromate", J. Org. Chem., 55, 23, pp. 5848-5850, 1990.

DOI: http://dx.doi.org/10.1021/jo00310a015

[4] M. K. Mahanti, "Kinetics of Oxidation of Nitrotoluenes by Acidic Hexacyanoferrate(III)", Bull .Korean Chem. Soc., 4, 3, pp. 120-123, 1983.

[5] G. P. Panigrahi, "Michaelis-Menten Behaviour in the Oxidation of Benzaldehydes by Pyridinium Chlorochromate", Bull. Korean Chem. Soc., 13, 5, pp. 547-550, 1992.

[6] M. K. Mahanti, B. Kuotsu, E. Tiewsoh, "Quinolinium Dichromate Oxidation of Diols: A Kinetics Study", J. Org. Chem., 61, 25, pp. 8875-8877, 1996.

DOI: http://dx.doi.org/10.1021/jo961079m

[7] H. B. Davis, R. M. Sheets, W.W. Pandler, "High Valent Chromium Heterocyclic Complexes-1l: New Selective and Mild Oxidants", Heterocycles, 22, 9, pp. 2029-2035, 1984.

DOI: http://dx.doi.org/10.3987/R-1984-09-2029

[8] M. R. Pressprich, R, D. Willett, H. B. Davis, "Peparation and Crystal Structure of Dipyrazinium Trichromate and Bond Length Correlation for Chromate Anions of the Form $\mathrm{Cr}_{\mathrm{n}} \mathrm{O}_{3 \mathrm{n}+1}{ }^{2-"}$, Inorg. Chem., 27, 2, pp. 260-264, 1988.

DOI: http://dx.doi.org/10.1021/ic00275a009

[9] M. H. Cho, J. H. Kim, H. B. Park, "Kinetic Study of Macrocyclic Ligand-Metal Ion Complexes", J. Korean Chem. Soc., 33, 4, pp. 366-370, 1989.

[10] G. D. Yadav, "Mechanistic and Kinetic Investigation of Liquid-Liquid Phase Transfer Catalyzed Oxidation of Benzyl Chloride to Benzaldehyde", J. Phys Chem., 101, 1, pp. 36-48, 1997.

DOI: http://dx.doi.org/10.1021/jp961678x

[11] M. K. Mahanti, "Kinetics and Mechanism of the Oxidative Cleavage of Unsaturated Acids by Quinolinium Dichromate”, Bull. Chem. Soc. Japan, 67,
8, pp. 2320-2322, 1994.

DOI: http://dx.doi.org/10.1246/bcsj.67.2320

[12] M. K. Mahanti, "Quinolinium Dichromate Oxidations Kinetics and Mechanism of the Oxidative Cleavage of Styrenes”, J. Org. Chem., 58, 18, pp. 4925-4928, 1993. DOI: http://dx.doi.org/10.1021/jo00070a031

[13] I. S. Koo, J. S. Kim, S. K. An, "Kinetic Studies on Solvolyses of Subsitituted Cinnamoyl Chlorides in Alcohol-Water Mixture", J. Korean Chem. Soc., 43, 5, pp. 527-534, 1999.

[14] R. Tayebee,"Simple Heteropoly Acids as Water Tolerant Catalysts in the Oxidation of Alcohols with 34\% Hydrogen Peroxide, A Mechanistic Approach", J. Korean Chem. Soc., 52, 1, pp. 23-29, 2008. DOI: http://dx.doi.org/10.5012/jkcs.2008.52.1.023

[15] R. Y. Sung, H. Choi, I. S. Koo, "Kinetic Studies on the Nucleophilic Substittution Reaction of 4-X-Subsitituted-2,6-dinitrochlorobenzene with Pyridines in MeOH-MeCN Mixtures", Bull. Korean Chem. Soc., 30, 7, pp. 1579-1582, 1988

[16] Y. S. Kim, H. Choi, I. S. Koo, "Kinetics and Mechanism of Nucleophilic Substittution Reaction of 4-Subsitituted-2,6-dinitrochlorobenzene with Benzylamines in MeOH-MeCN Mixtures", Bull. Korean Chem. Soc., 31, 11, pp. 3279-3282, 2010. DOI: http://dx.doi.org/10.5012/bkcs.2010.31.11.3279

[17] M. H. Cho, J. H. Kim, and H. B. Park, "Kinetic Study of Macrocyclic Ligand-Metal Ion Complexes", J. Korean Chem. Soc., 33, pp. 366-371, 1989.

[18] G. D. Yadav, "Mechanistic and Kinetic Investigation of Liquid-Liquid Phase Transfer Catalyzed Oxidation of Benzyl Chloride to Benzaldehyde", J. Phys. Chem., 101, pp. 36-40, 1997.

[19 M. K. Mahanti, "Kinetics and Mechanism of the Oxidative Cleavage of Unsaturated Acids by Quinolinium Dichromate", Bull. Chem. Soc. Japan., 67, pp. 2320-2324, 1994.

[20] D. Richard and Gilliom, Physical Organic Chemistry", pp. 169-180, 1992.

[21] M. K. Mahanti, "Quinolinium Dichromate Oxidations Kinetics and Mechanism of the Oxidative Cleavage of Styrenes", J. Org. Chem., 58, pp. 4925-4928, 1993. DOI: http://dx.doi.org/10.1021/jo00070a031 
김 영 식(Young-Sik Kim)

[정회원]

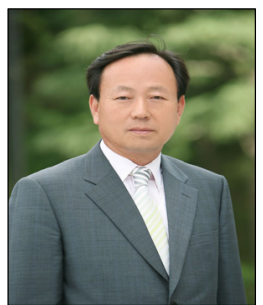

- 1979년 2월 : 충북대학교 대학원 화학공학과 (공학석사)

- 1989년 2월 : 충북대학교 대학원 화학공학과 (공학박사)

- 1996년 8월 1997년 8월 : 영 국 Strathclyde Univ. 방문교수

- 2010년 2월 2011년 2월 : 미 국 Eastern Michigan Univ. 방문 교수

- 2011년 11월 현재 : 한국가스안전공사 비상임이사

- 1982년 2월 현재 : 강원대학교 화학공학과 교수

<관심분야>

레올로지, 분리정제, 정밀화학

박 영 조(Young-Cho Park)

[정회원]

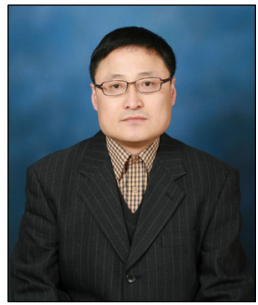

- 1993년 8월 : 경남대학교 대학원 화학과 (이학박사)

- 1995년 3월 2007년 2월 : 부 산대학교 밀양캠퍼스 강사

- 2008년 9월 2009년 8월 : 강 원대학교 삼척캠퍼스 겸임교수

- 2009년 8월 현재 : 강원대학 교 삼척캠퍼스 강사

<관심분야>

반응속도론, 정밀화학 